\title{
Blickdiagnose
}

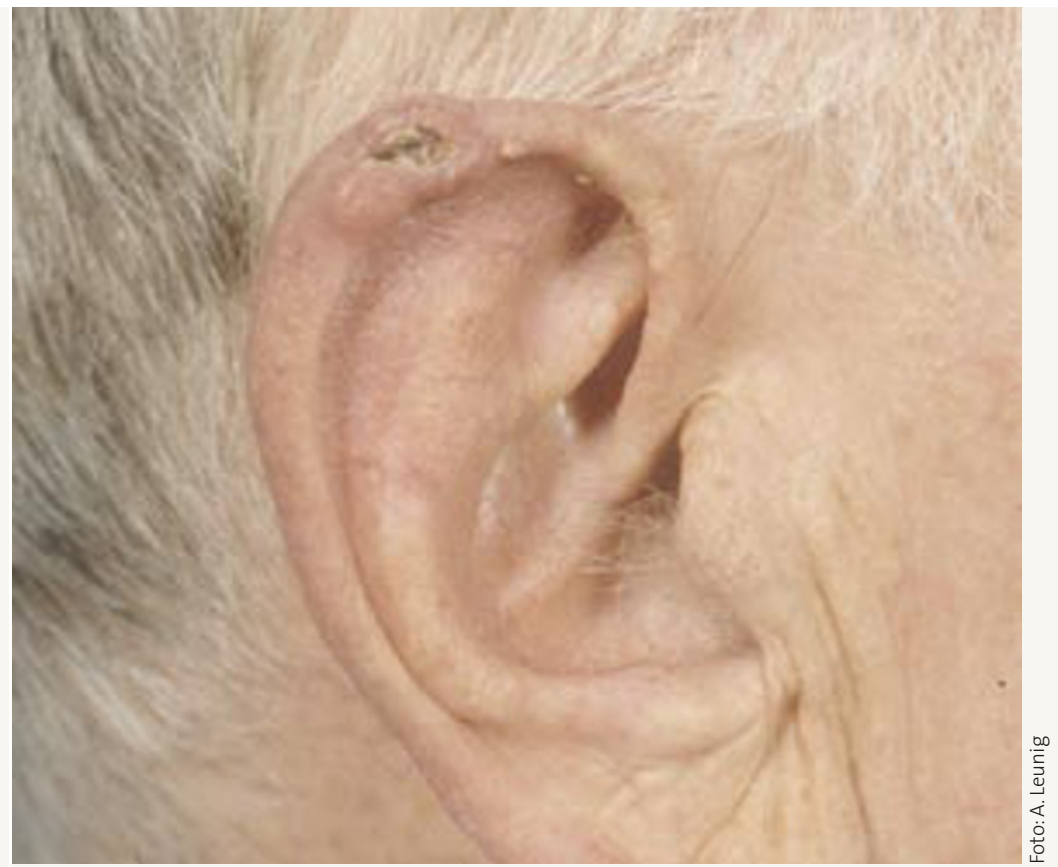

\section{Zu viel Sonne am Ohr}

Ein 65-jähriger Patient kam in die Sprechstunde und berichtete über eine nicht schmerzhafte, nässende und gelegentlich blutende Wunde am oberen freien Ohrmuschelrand.

Klinisch zeigt sich das Bild eines malignen Hauttumors der Ohrmuschel. Prädisponierende Faktoren sind chronische Sonneneinstrahlung bei Landarbeitern und Bauern, chronische Hautinfektionen, Psoriasis oder chemische Verätzungen.

Die endgültige Diagnose erfolgt histologisch nach Entnahme einer Gewebsbiopsie. Häufigste Befunde sind Basaliome, gefolgt von Plattenepithelkarzinomen.

Die Therapie stellt immer die vollständige Tumorresektion mit nachfolgender Rekonstruktion dar. Im Falle von Plattenepithelkarzinomen muss der Lymphabflussweg bildgebend kontrolliert werden und ggf. auch eine NeckDissection durchgeführt werden.

Die Prognose ist bei vollständiger Resektion von Basaliomen sehr gut. Für Plattenepithelkarzinome beträgt die 5-Jahres-Überlebensrate für alle Stadien etwa $80 \%$.

- Priv.-Doz. Dr. med. Andreas Leunig, Oberarzt, Klinik und Poliklinik für Hals-NasenOhren-Heilkunde der Ludwig-Maximilians-Universität München

Keyword: Basal cell carcinoma, squamous cell carcinoma

\section{Ihr besonderer Fall?}

Sicher sehen auch Sie ab und an einen besonders eindrucksvollen Befund in Ihrer Praxis. Fotografieren Sie ihn, schreiben Sie uns unter dem Stichwort Blickdiagnose, bei Veröffentlichung erhalten Sie 100 Euro.

MMW-Fortschritte der Medizin

E-Mail:manhart@urban-vogel.de

Fax: 089/4372-1420

Weitere interessante Blickdiagnosen finden Sie in unserem Online-Archiv unter www.mmw.de. 